$$
\text { DOE/PC/89789. T4 }
$$

Technical Progress Report

for the

$\mathrm{DOE} / \mathrm{PC} / 89789--\mathrm{T} 4$

DE92 01.2561

Ninth Quarter

September 1 - November 30, 1991

Control of Pyrite Surface Chemistry in Physical Coal Cleaning

by

R.-H. Yoon, G. H. Luttrell, J.B. Zachwieja, and J.A. Mielczarski

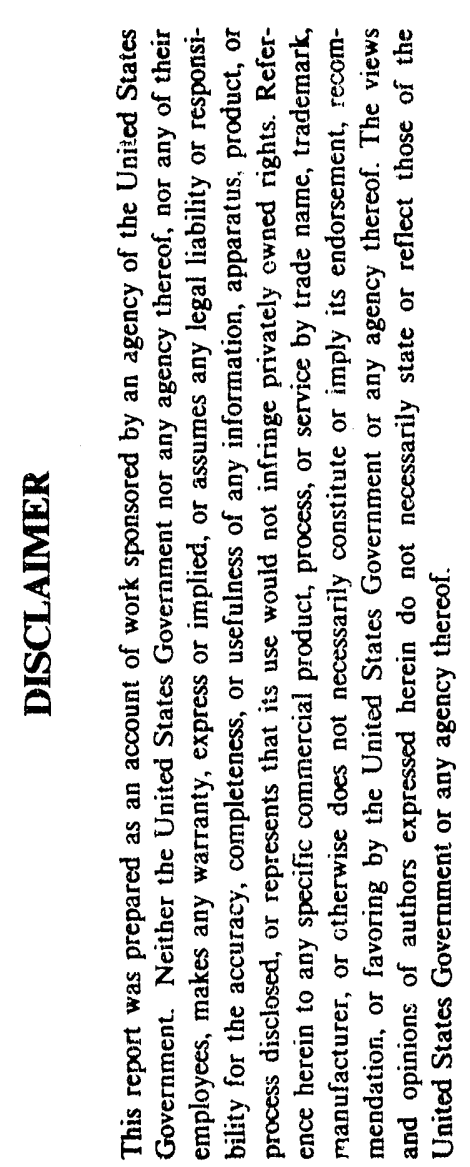

Virginia Center for Coal and Minerals Processing Department of Mining and Minerals Engineering Virginia Polytechnic Institute and State University Blacksburg, Virginia 24061-0258

\author{
Grant Number: \\ DE-FG22-89PC89789
}

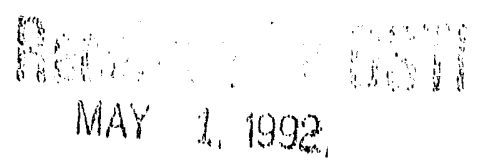

\title{
Program Officer:
}

Robert Dolence

U.S. Department of Energy

Pittsburgh Energy Technology Center

Pittsburgh, Pennsylvania

U.S.DOE patent clearance is not required prior to publication of this document. 


\begin{abstract}
The separation of pyrite from coal by flotation is based on exploiting the wettability difference between coal and pyrite. There is evidence that the wettability of coal pyrite changes upon superficial oxidation. Therefore, the oxidation of coal pyrite has been studied under carefully controlled electrochemical conditions. In order to identify the species responsible for the changes in wettability, the surface products formed during oxidation have been identified by means of yarious surface analysis techniques, including X-ray photoelectron spectroscopy (XPS) and ion scattering spectroscopy (ISS). It has been found that pyrite oxidation creates a sulfur-rich surface along with iron oxides/hydroxides. The ratio between these hydrophobic and hydrophilic species correlates well with the results of the wettability measurements.
\end{abstract}

\title{
INTRODUCTION
}

One of the foremost contributors to poor pyrite rejection in coal flotation is incomplete liberation. But incomplete liberation is not the only cause of poor pyrite rejection, as suggested by the frequent recovery of well-liberated particles of pyrite in the clean coal products in processes based on exploiting the differences in the surface properties of coal and coal pyrite. Numerous reports have suggested that sulfide minerals may be naturally hydrophobic. However, more recent investigations have shown that the apparent hydrophobicity of sulfide minerals, frequently observed during flotation, is actually induced by superficial oxidation (Heyes and Trahar, 1977; Gardner and Woods, 1979; Luttrell and Yoon, 1984; Zachwieja et al., 1989; Ahlberg et al., 1990). 
In a previous paper (Yoon et al., 1991), the hydrophobicity of coal pyrite was found to depend upon the superficial oxidation of the sample. XPS analysis of the oxidized surfaces suggested that sulfur-rich surfaces formed during oxidation and that they may be responsible for the hydrophobicity. An oxidation mechanisn was proposed involving the production of metal polysulfides and iron oxides/hydroxides as the species governing hydrophobicity.

The present work presents additional information on the causes for the hydrophobicity of coal pyrite observed during flotation. Electrochemical measurements were conducted to define the reduction/oxidation behavior of both coal and mineral pyrite. Surface analysis techniques (XPS and ISS) ware used to identify the surface products of reduction/oxidation processes. Microflotation measurements were employed to correlate changes in hydrophobicity with the nature of the surface products determined by spectroscopic techniques.

\section{EXPERIMENTAL}

\section{Materials}

Rectangular slabs of pyrite (Logrono, Spain) and coal pyrite (Pittsburgh No. 8 seam) were used for electrochemical and spectroscopic characterization. The supporting electrolyte used in these studies was $1 \mathrm{M} \mathrm{KCl}$, which produced a solution of near neutral $\mathrm{pH}$. Ultra high purity nitrogen was used for purging the solution.

\section{Electrochemical measurements}

A standard three-electrode electrochemical cell was used for open-circuit potential m'asurements, cyclic voltammetry, and for the electrochemical pretreatment of the samples 
prior to their spectroscopic analysis. The pyrite specimen served as the working electrode, while a platinum wire mesh was used as the counter electrode, and a silver-chloride electrode was used as the reference electrode. All potentials are reported against the standard hydrogen electrode (SHE) scale.

The slab electrode was initially rough-polished using different grades of silicon carbide papers. The final polishing was done using $0.3-$ and $0.05-\mu \mathrm{m}$ alumina powder. After polishing, the electrode was washed successively in an ultrasonic bath in warm ethyl alcohol, in a $10 \% \mathrm{H}_{2} \mathrm{SO}_{4}$ solution for 15 seconds, and then in $18 \mathrm{M} \Omega$ deionized water. The electrode was then transferred immediately to the electrochemical cell. Cyclic voltammograms were recorded after the insertion of the electrode into the cell. For spectroscopic analysis, the electrode potential was stepped from the open-circuit value to the desired potential and held for 10 minutes. The electrode was then removed from the cell, quickly rinsed with deionized water and blown dry with nitrogen, and inserted into the spectrometer for analysis. After each spectrum was recorded, the electrode was polished for the next measurement.

\section{Spectroscopic analysis}

The XPS spectra were recorded on a Perkin-Elmer PHI 550 spectrometer with $\mathrm{K} \alpha$ excitation from a magnesium anode op rated at $10 \mathrm{kV}$ and $10 \mathrm{~mA}$. The pressure in the analyzer chamber was nearly $10^{-8} \mathrm{~Pa}$. The measurements were performed with a take-off angle close to $45^{\circ}$. Narrow scan spectra were collected for the oxygen (Ols), carbon $(\mathrm{Cls})$, sulfur (S2p), and iron (Fe2p and Fe3p) lines. The S2p, O1s, Fe3p, and Fe2p lines were 
f:tted with a mixture of Gaussian and Lorentzian peak shapes (maximum of $20 \%$ Lorentzian). The binding energies were referenced to the $\mathrm{C} 1 \mathrm{~s}$ peak at $284.9 \mathrm{eV}$.

The ISS examination of the sample was performed in conjunction with the XPS measurements. After evacuation to nearly $10^{-9} \mathrm{~Pa}$, the vacuum chamber was backfilled to 2 $\mathrm{x} 10^{-5} \mathrm{~Pa}$ with pure helium. The primary energy of $1 \mathrm{keV}$ was used with a beam current density of $9 \mu \mathrm{A} / \mathrm{cm}^{2}$. The sputtering process was sufficiently slow to measure a depth profile within approximately 10 minutes. The backscattercd ${ }^{3} \mathrm{He}^{+}$ions were measured at $123^{\circ}$ for analysis of the surface.

\section{Microflotation}

To minimize oxidation the coal pyrite sample used in the present work was crushed, ground, and wc.-screened to obtain the $-100+150$ mesh (U.S.) fraction just prior to each flotation experiment.

Dowfroth M-150, a polypropylene glycol methyl ether with a molecular weight of approximately 400 , was used as frother in the experiments. Industrial grade kerosene was used as a collector. The solution of $\mathrm{pH}$ was controlled by addition of either acid $(\mathrm{HCl})$ or base $(\mathrm{KOH})$ to a $1 \mathrm{M} \mathrm{KCl}$ solution.

Approximately three grams of the $-1 n+150$ mesh (U.S.) or coal pyrite was conditioned in a beaker containing $120 \mathrm{ml}$ of the $\mathrm{pH}$ adjusted electrolyte solution for 5 minutes. The sample and solution were then transferred to a Fartridge and Smith (1971) - type cell and a two-minute flotation was conducted using nitrogen as the carrier gas. The percentage floatability was determined from the oven-dried weight of the material collected in the cell launder. 


\section{RESULTS AND DISCUSSION}

\section{Open circuit potential:}

The open circuit potentials of freshly polished coal and mineral pyrite electrodes as a function of solution $\mathrm{pH}$ are shown in Figure 1. There appears to be little difference between the open-circuit potentials recorded for the coal and mineral pyrite samples examined in these measurements. It is well known that a thin oxide film forms on pyrite polished in air (Buckley et al., 1988) and that the presence of this film can influence the open-circuit potential measured in the system. The small differences in the open-circuit potentials observed for the coal and mineral pyrite samples suggest that the surface products formed on each may be similar.

\section{Cyclir Voltammetry}

Steady-state cyclic voltammograms of stationary mineral and coal pyrite electrodes in $1 \mathrm{M} \mathrm{KC1}$ solution are shown in Figure 2. The voltammograms for both samples are very similar, showing four anodic and three cathodic peaks. These peaks are numbered I-VII for the ease of reference in the following discussion pertaining to both electrodes.

The first three peaks, I-III, correspond to the oxidation of iron species. According to Ahlberg et al. (1990), peak I can be attributed to the oxidation of elemental iron. Iron (II) hydroxide is typically formed in this region; however, when iron is oxidized in the presence of hydrosulfide ions, iron sulfide (FeS) may be formed. Peaks II and III correspond to the oxidation of iron (II) hydroxide and FeS formed at peak I, respectively. Moreover, elemental sulfur can be formed in this region from the oxidation of hydrosulfide ions. Pyrite oxidation occurs close to the open-circuit potential and continues at higher potentials as 
evidenced by the dramatic increase in current for peak IV. Hamilton and Woods (1981) described the oxidation of pyrite in alkaline solution by the following reactions:

$$
\mathrm{FeS}_{2}+3 \mathrm{H}_{2} \mathrm{O} \rightarrow \mathrm{Fe}(\mathrm{OH})_{3}+2 \mathrm{~S}^{\circ}+3 \mathrm{H}^{+}+3 e^{-}
$$

in which only monolayer quantities of elemental sulfur are formed, while the majority of the sulfur is oxidized to sulfate with increasing overpotential by reaction,

$$
\mathrm{FeS}_{2}+11 \mathrm{H}_{2} \mathrm{O} \rightarrow \mathrm{Fe}(\mathrm{OH})_{3}+2 \mathrm{SO}_{4}^{2-}+19 \mathrm{H}^{+}+15 e^{-}
$$

Most recently Buckley et al. (1988(a)) reformulated reaction (1) on the basis of more detailed XPS and electrochemical measurements and described the oxidation in terms of the formation of a sulfur-rich or metal-deficient surface:

$$
\mathrm{FeS}_{2}+3 \mathrm{xH}_{2} \mathrm{O} \rightarrow \mathrm{xFe}(\mathrm{OH})_{3}+\mathrm{Fe}_{1-x} \mathrm{~S}_{2}+3 x \mathrm{H}^{+}+3 x e^{-}
$$

Mycroft et al. (1990) reached the conclusion that the electrochemical oxidation of pyrite surfaces in near neutral aqueous solutions produces polysulfides and elemental sulfur as evidenced from Raman spectroscopy of the surface.

On the reverse scan, cathodic peak $V$ occurs and is coupled with the anodic processes occurring at peak IV. Mycroft et al. (1990) postulated that this redox couple is associated with the oxidation and reduction of a sulfur species since iron is already in the ferric state. Moreover, from their raman and XPS results, this potential region is known to be an active 
region for the formation of polysulfide and sulfur. Peak VI corresponds to the reduction of oxidic species produced in reactions (1-3) by the following reactions:

$$
\begin{gathered}
\mathrm{Fe}(\mathrm{OH})_{3}+\mathrm{H}^{+}+e^{--} \rightarrow \mathrm{Fe}(\mathrm{OH})_{2}+\mathrm{H}_{2} \mathrm{O}, \\
\mathrm{Fe}(\mathrm{OH})_{3}+S^{\circ}+3 e^{-} \rightarrow \mathrm{FeS}+30 \mathrm{H} .
\end{gathered}
$$

The reduction of bulk pyrite, iron sulfide, and iron (II) hydroxide occurs at more negative potentials in the region of peak VII. In this region elemental iron forms on the electrode surface while hydrosulfide ions are released to the solution.

\section{Surface analysis}

Surface analysis of a polished coal pyrite electrode by X.'S shows that the $S 2 p / F e 3 p$ ratio is 2.9 and the positions of the $S 2 p_{3 / 2}$ and $F e 2 p_{3 / 2}$ peaks on the narrow scans are 162.8 and $707.5 \mathrm{eV}$, respectively. Oxidation at potentials below the region of peak IV (Fig.2) resulted in only minor changes in the XPS spectra. Shown in Figure 3 are the differences in the $\mathrm{S} 2 \mathrm{p}, \mathrm{Fe} 2 \mathrm{p}_{3 / 2}$, and $01 \mathrm{~s}$ lines for a coal pyrite electrode oxidized for 10 minutes at $0.3 \mathrm{~V}$ (SHE), open-circuit potential, and at $0.7 \mathrm{~V}$ (SHE). At the open-circuit potential, the S2p, $\mathrm{Fe} 2 \mathrm{p}_{3 / 2}$, and $\mathrm{O} 1 \mathrm{~s}$ narrow scans are unchanged from freshly polished pyrite. However, the $\mathrm{S} 2 \mathrm{p} / \mathrm{Fe} 3 \mathrm{p}$ ratio is 3.3 , which reflects a small change in the relative amount of surface sulfur. A dramatic change in the narrow scans occurs when the electrode is oxidized for 10 minutes at $0.7 \mathrm{~V}$ (SHE). The S2p narrow scan shows a significant broadening to higher binding energies and the $S 2 p / F e 3 p$ ratio increases to 7.5 . This suggests that additional sulfur species 
are present on the electrode surface. The Fe2 $\mathrm{p}_{3 / 2}$ narrow scan looks similar to the scan at open circuit except that the intensity is greatly diminished. Moreover, additional intensity occurs from $711-712 \mathrm{eV}$. Since the Fe2p line is more surface sensitive than the Fe3p line, the lower overall intensity of the $\mathrm{Fe} 2 \mathrm{p}$ line together with the additional intensity at $711 \mathrm{eV}$ suggest that an overlayer is present on the electrode surface. This is supported further by the fact that the Ols narrow scan shows a significant increase in the component attributed to hydroxides at $532 \mathrm{eV}$.

Illustrated in Figure 4 are the difference in the line shape and binding energy of the S2p narrow scan for the coal pyrite electrode oxidized at the open-circuit potential and at $0.7 \mathrm{~V}$ (SHE). The S2p line is a spin-split doublet, in which the $2 \mathrm{p}_{3 / 2}$ and $2 \mathrm{p}_{1 / 2}$ components are separated by $1.2 \mathrm{eV}$ and have an intensity ratio of $2: 1$. The $\$ 2 \mathrm{p}$ line at open circuit can be curve fit with one spin-split doublet, which indicates the presence of only one sulfur species, namely $\mathrm{S}_{2}{ }^{2}$, at $162.8 \mathrm{eV}$. However, the S2p line for the coal pyrite electrode oxidized at $0.7 \mathrm{~V}$ (SHE) is more complex. The $\mathrm{S} 2 \mathrm{p}$ line is broader towards the higher binding energy side of the spectrum and can be curve fit with at least three spin-split doublets. The lowest binding energy doublet corresponds to pyritic sulfur at $162.7 \mathrm{eV}$. The highest binding energy doublet occurs close to that reported for elemental sulfur at $164 \mathrm{eV}$. The third doublet is intermediate between those for pyritic sulfur and elemental sulfur and occurs at $163.4 \mathrm{eV}$, suggesting a polysulfide (Mycroft et al., 1990; Buckley et al., 1988(b); Termes et al., 1987).

The XPS results suggest that the sulfur environment of the coal pyrite electrode changes upon oxidation. Curve fits of the S2p line reveal additional sulfur species present on 
the electrode surface. This additional sulfur is at a higher oxidation state than the lattice sulfur. This oxidation layer, which contains the additional sulfur species, is most probably several atomic layers thick, because of the significant attenuation of the Fe2p signal. The stability of these additional sulfur species was determined by extended exposure to high vacuum. The position and intensity of each component did not change appreciably after 4 hours exposure to the high vacuum. This indicates that the overlayer is stable and that the elemental sulfur-like species present in the overlayer most probably represents the sulfur atoms in a metal polysulfide molecule most remote from the sulfur atoms closest to the metal atom.

Low energy ion scattering spectroscopy (ISS), using ${ }^{3} \mathrm{He}^{+}$ions of an oxidized coal pyrite electrode results in the time dependent spectra shown in Figure 5. The scattered ion intensity is plotted as a function of the scattered ion energy ratio, E/E $\mathrm{E}_{0}$. The initial ISS spectrum, at the $t=0$ seconds, reveals peaks corresponding to oxygen and sulfur. There is no evidence of iron on the initial spectra for oxidized coal pyritc. The initial ISS spectrum of freshly polished coal pyrite shows iron, in addition to sulfur and oxygen, with a $\mathrm{S} / \mathrm{Fe}$ ration of $2: 1$. The steeply increasing intensity with decreasing $E / E_{0}$ (Fig. 5) indicates the presence of adventitious carbon. The chief advantage of ISS lies in its high sensitivity for the first atomic layer. With this in mind, the initial ISS spectra indicates that the outermost surface of the oxidized coal pyrite electrode is composed of an overlayer containing oxygen and sulfur species, as well as hydrocarbon contamination. This finding supports the interpretation made from the XPS measurements that the oxidation layer contains additional sulfur species. 
The ISS spectra were recorded at regular intervals during the low energy sputtering. After about 200 seconds of sputtering, an iron peak is observed in the spectra. The sulfur and iron peaks continue to grow with increased sputtering time and reach a constant level after about 10 minutes. This is better seen in the depth profile shown in Figure 6. The element area is plotted as a function of the sputter time. Three distinct regions are seen on the plot with respect to the iron. Below 100 seconds the ISS spectra is dominated by sulfur, oxygen, and carbon. From 100 to 350 seconds the concentration of iron increases and reaches a plateau, while the amount of sulfur constantly increases with the amount of oxygen slowing decreasing. The slow increase in iron along with the continuous increase in sulfur may represent the penetration of the helium ions through a sulfur-rich layer. This sulfur-rich layer most probably is composed of polysulfides and a small amount of iron oxide/hydroxides. After about 350 seconds, the sulfur reaches a plateau, while the iron increases and the oxygen continues to decrease slowly. At close to 10 minutes the $\mathrm{S} / \mathrm{Fe}$ ratio is $2: 1$, indicating that the underlying pyrite has been reached.

A different sitjation occurs when the coal pyrite is oxidized in an alkaline solution. The depth profile for oxidized coal pyrite from low energy sputtering is shown in Figure 7. Only oxygen and iron are detected over a 10 minute sputter time. The XPS spectrum of this sample reveals an overlayer of iron oxide/hydroxide that completely attenuates the sulfur signal. A sulfur signal can be detected only after medium energy sputtering with argon gas at $3 \mathrm{keV}$. The oxidation layer produced on coal pyrite in alkaline solution differs from the oxidation layer produced in near neutral solution. In near neutral solution, additional sulfur species are incorporated in the overlayer along with small amounts of iron oxide/hydroxides. 
In alkaline solution, a thick overlayer composed solely of iron oxide/hydroxides results from oxidation.

\section{Microflotation}

The hydrophobicity of coal pyrite particles was observed during microflotation measurements. The results of microflotation floatability as a function of solution $\mathrm{pH}$ for coal pyrite are shown in Figure 8. Freshly ground coal pyrite in the presence of frother alone exhibits the lowest level of hydrophobicity (curve A). When collector is added to the system the floatability increases significantly over the examined $\mathrm{pH}$ range (curve B). Maximum floatability is obtained between $\mathrm{pH} 8-9$, with the floatability decreasing above and below this region.

When the coal pyrite sample is conditioned for 30 minutes, frior to the flotation, the resulting floatability in the presence of frother alone is significantly higher than for the freshly ground sample (curve C). This is expected since the surface analysis measurements described above revealed that a sulfur-rich overlayer is formed on oxidized coal pyrite in near neutral solution. The hydrophobicity of the oxidized coal pyrite decreases rapidly with increasing solution $\mathrm{pH}$. Again, this is not unusual and, as discussed above, from the XPS and ISS data in alkaline solution, the deterioration in hydrophobicity can be related to the production of an overlayer containing mostly hydrophilic iron oxide/hydroxides.

The overall level of floatability for the oxidized coal pyrite is comparable to that observed for the freshly ground sample in the prisence of flotation reagents. However, the freshly ground sample in the presence of Dowfroth M-150 and kerosene exhibits higher floatability in the alkaline $\mathrm{pH}$ region. This is believed to be due to the adsorption of these 
reagents on the coal pyrite, which is weakly hydrophobic for the reasons given above, by means of the hydrophobic interaction force. Although its origin is still uncertain, this force was measured directly (Pashley and Israelachvili, 1981), and was recognized as the major force for the attraction between hydrophobic substances (Xu and Yoon, 1989, 1990).

The largest difference in hydrophobicity is observed when coal pyrite contaminated with coal pyrite that has been contaminated with coal inclusions is floated in the presence of frother and collector (Fig.8, curve D). The contaminated coal pyrite exhibits the highest floatability across the entire $\mathrm{pH}$ range. This behavior illustrates the difficulty in separating composite particles (or middlings) from completely liberated coal particles. Even a small inclusion of coal in a pyrite/coal composite particie can readily induce bubble-particle attachment, causing the pyrite to report to the clean coal product.

\section{CONCLUSION}

The hydrophobicity of coal pyrite can be related to the surface products formed during oxidation in aqueous solutions. A sulfur-rich surface layer is produced during oxidation in near neutral pH solutions. This surface layer is composed mainly of sulfur species in the form of an iron polysulfide along with a smaller amount of iron oxide/hydroxides. The XPS and ISS data show that the surface layer has an overlayer-type structure on the pyrite surface with the hydrophobic sulfur species in the outermost region. Oxidation of coal pyrite in alkaline solutions produces a surface layer containing only iron and oxygen species most probably in the form of hydrophilic iron oxide/hydroxides. The spectroscopic data reveal that this surface layer is somewhat thicker than the layer produced at near neutral $\mathrm{pH}$ because the sulfur signal is completely attenuated. The limited hydropho- 
bicity observed for coal pyrite in alkaline solution may be attributed to the iron oxide/hydroxides forming in patches on the surface. Finally, the floatability of coal pyrite increases dramatically in the presence of frothers and hydrocarbon collectors. These reagents may absorb on a weakly hydrophobic surface by the hydrophobic interaction force.

\section{REFERENCES}

Ahlberg,E., Forssberg, K.S.E., and Wang, X., 1990, J. Appl. Electrochem., 20, 1033.

Buckley, A.N., Hamilton, I.C., and Woods, R., 1988(a), in Proc. Int. Symp. Electrochemis try in Minerai and Metal Processing II, P.E. Richardson and R. Woods, eds., The Electrochemical Society, New Jersey, 234.

Buckley, A.N., Wouterlood, H.J., Ca wright, P.S., and Gillard, R.D., 1988(b), Inorg. Chim. Acta., 143, 77.

Gardner, J.R. and Woods, R., 1979, Int. J. Miner. Process., 6, 1.

Hamilton, I.C. and Woods, R., 1981, J. Electroanal. Chem., 118, 327.

Heyes, G.W. and Trahar, W.J., 1977, Int. J. Miner. Process., 4, 317.

Luttrell, G.H. and Yoon, R.H., 1984, Colloids and Surfaces, 12, 239.

Mycroft, J.R., Bancroft, G.M., McIntyre, N.S., Lorimer, J.W., and Hill, I.R., 1990, J. Electroanal. Chem., 292, 139.

Partridge, A.C. and Smith, G.W., 1971, Trans. Inst. Min.Metall., Sec. C, 80, C199.

Pashley, R.M. and Israelachivili, J.N., 1981, Colloids and Surfaces, 2, 169.

Termes, S.C., Buckley,A.N., and Gillard, R.D., 1987, Inorg. Chim. Acta., 126, 79.

Xu, Z. and Yoon, R.H., 1989, J. Colloid Interface Sci. 132, 532. 
Yoon, R.H., Lagno, M.L., Luttrell, G.H., and Mielczarski, J.A., 1991, in Processing and Utilization of High Sulfur Coals (IV), Elsevier Science Publishers, New York.

Zachwieja, J.B., McCarron, J.J., Walker, G.W., and Buckley, A.N., 1989, J. Colloid Interface Sci., 132, 462. 


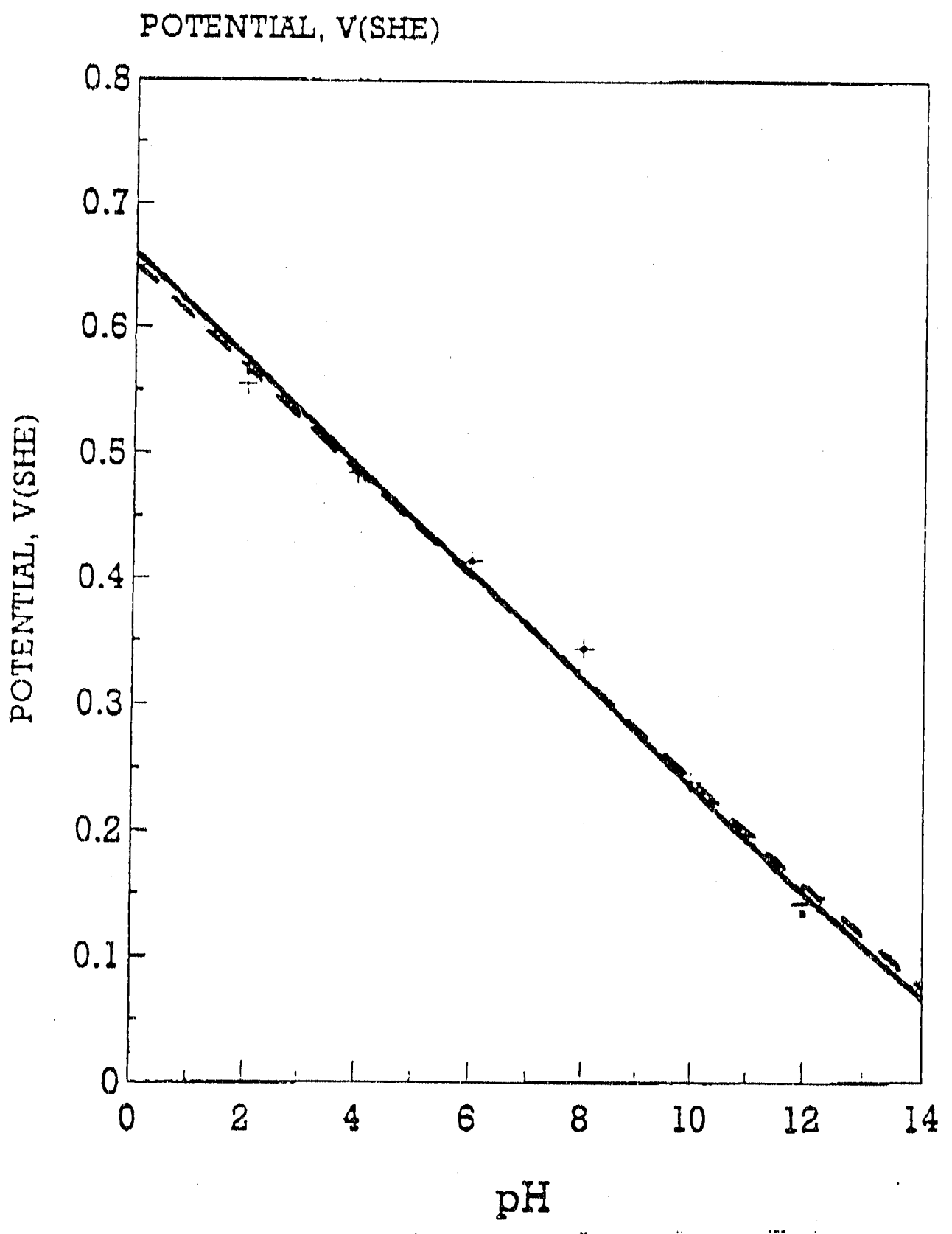

Figure 1. Open-circuit potentials of mineral pyrite and coal pyrite as a function of $\mathrm{pH}$. 


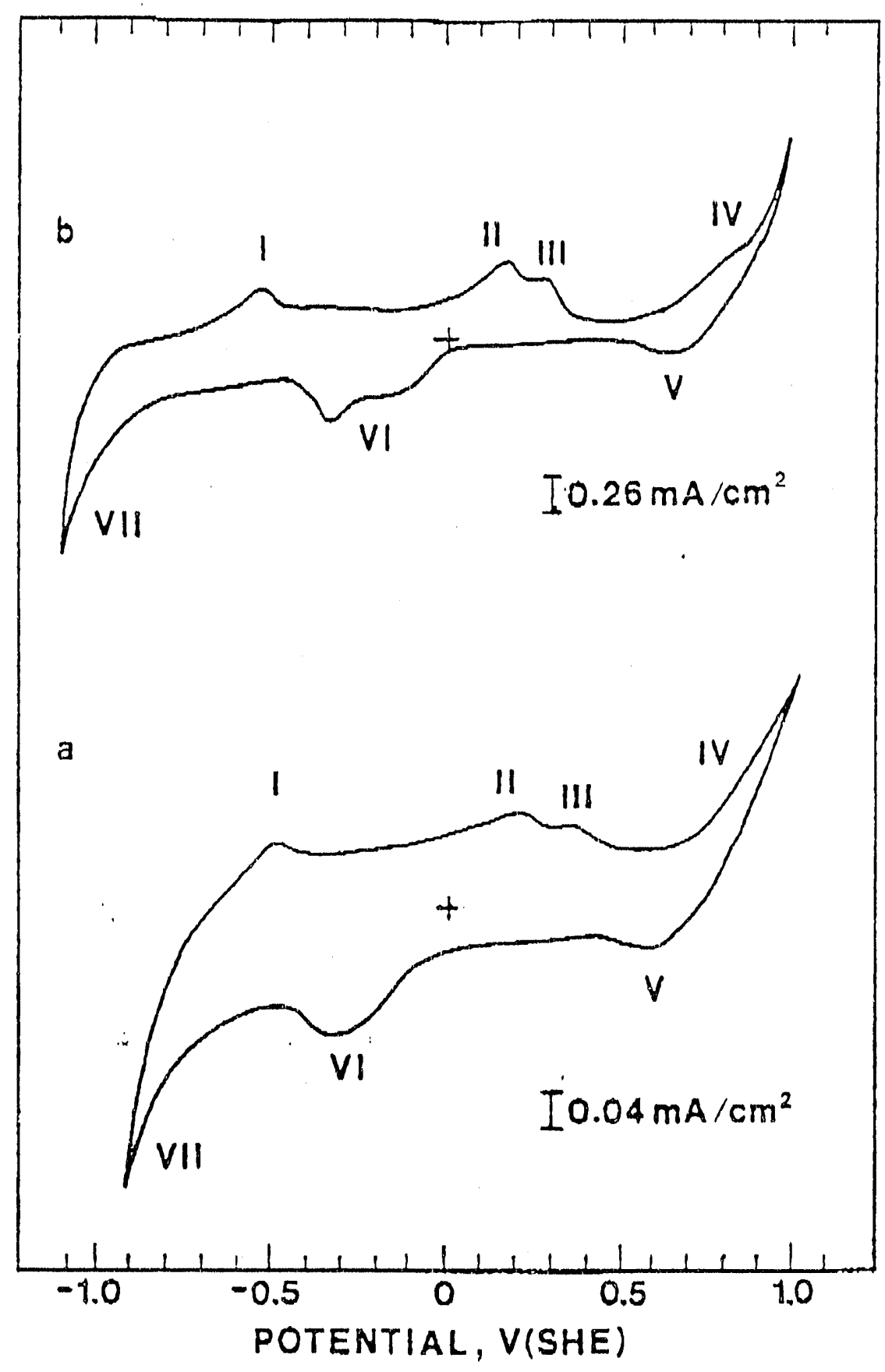

Figure 2. Cyclic voltammograms of (a) coal pyrite and (b) mineral pyrite in $1 \mathrm{M} \mathrm{KCl}$ at $25 \mathrm{mV} / \mathrm{sec}$. 


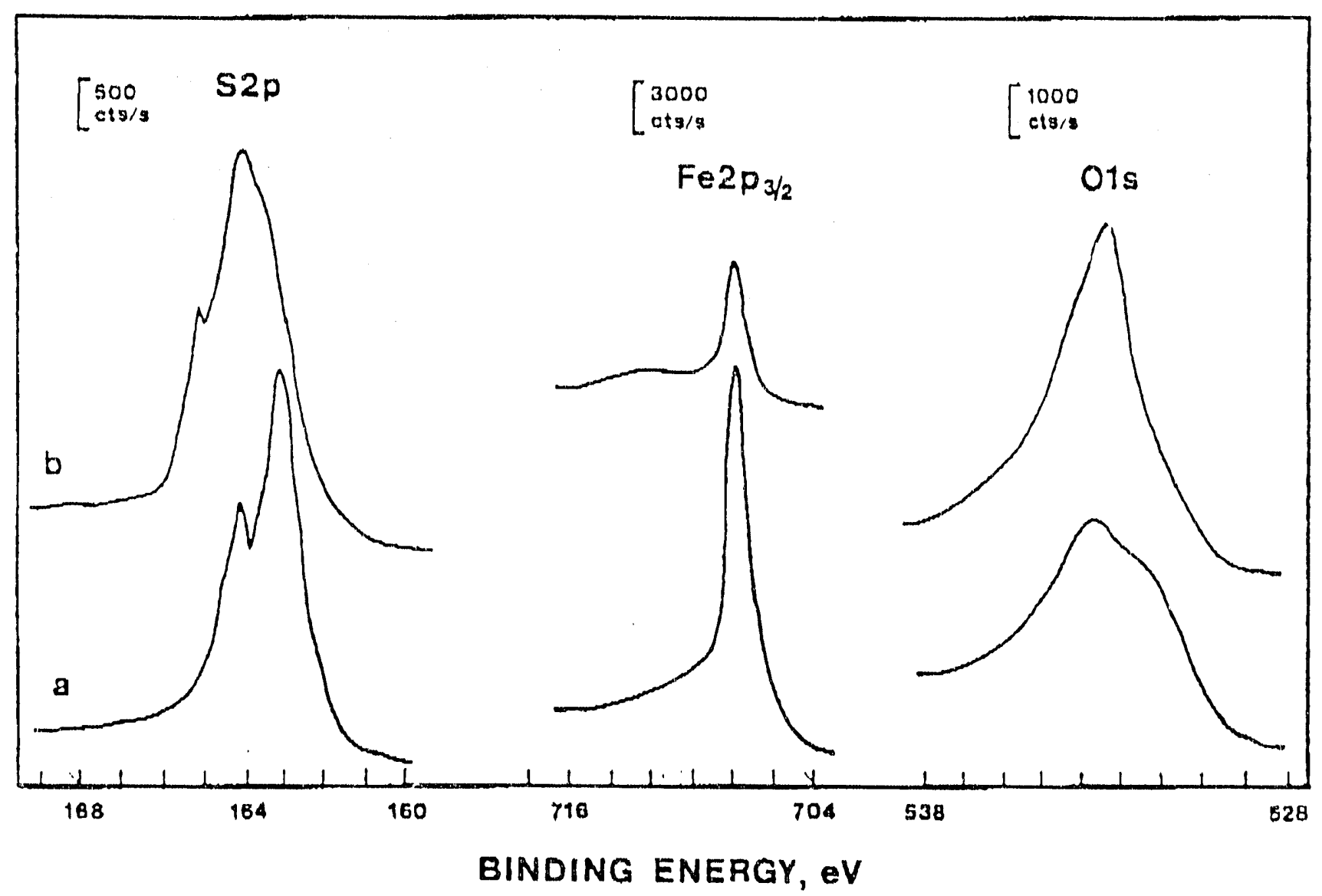

Figure 3. $\quad 32 \mathrm{p}, \mathrm{Fe} 2 \mathrm{p}_{3 / 2}$, and O1s XPS spectra for coal pyrite oxidized at (a) open circuit and (b) $0.7 \mathrm{~V}$ (SHE) for 10 minutes in $1 \mathrm{M} \mathrm{KCl}$. 


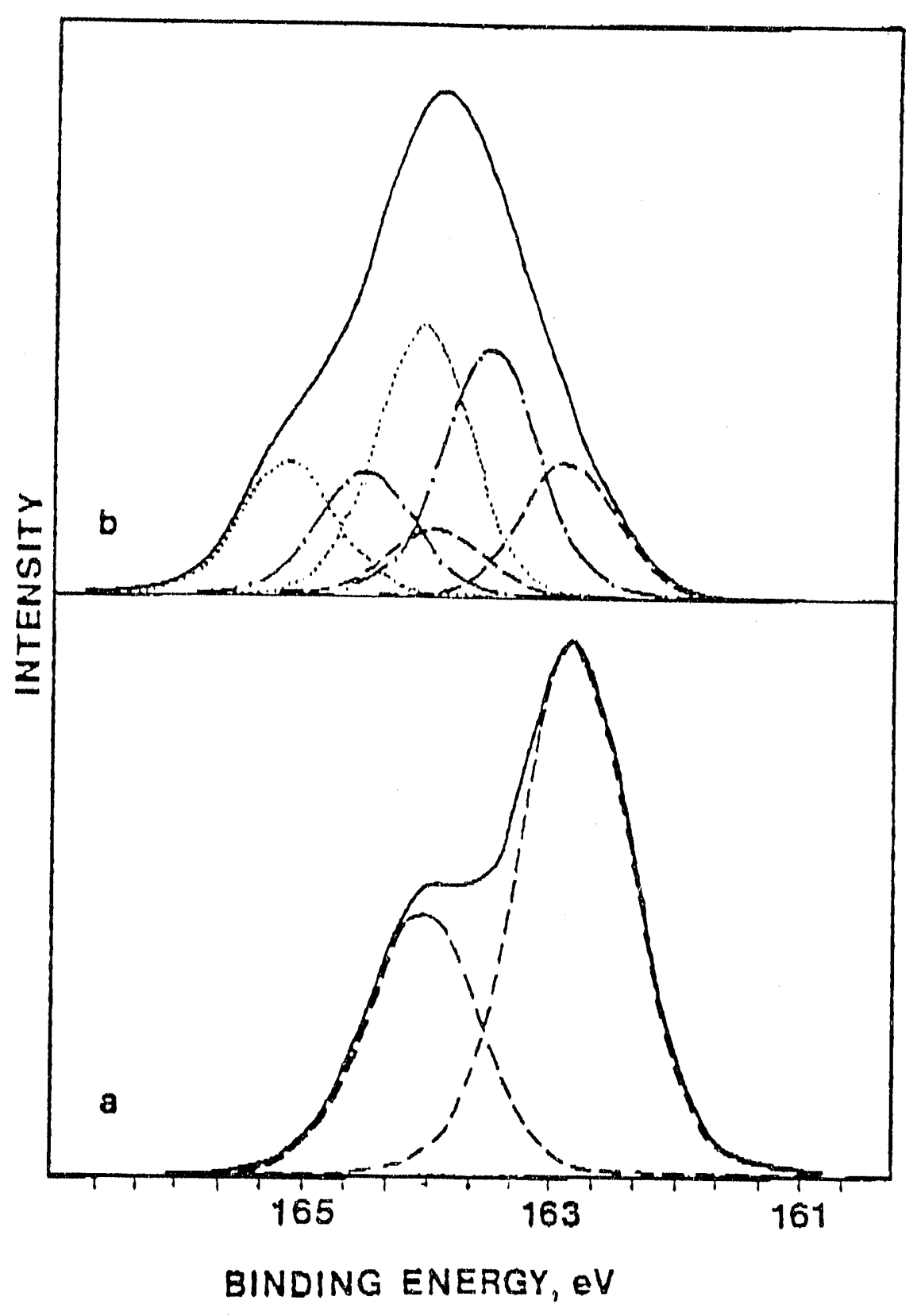

Figure 4. S2p spectra for coal pyrite oxidized at (a) open circuit and (b) $0.7 \mathrm{~V}$ (SHE) for 10 minutes in $1 \mathrm{M} \mathrm{KCl}$. 


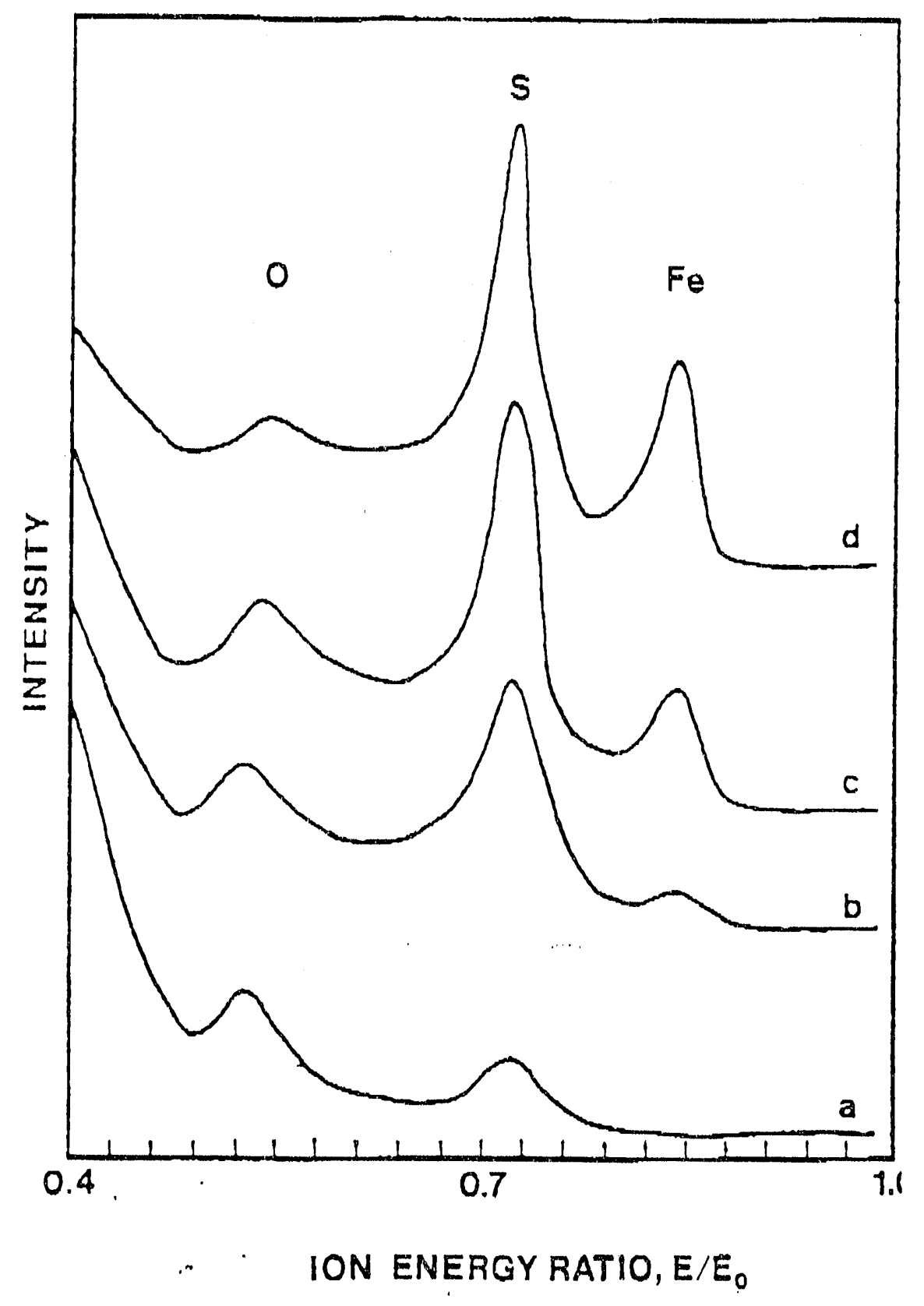

Figure 5. ISS spectra for coal pyrite oxidized at $0.7 \mathrm{~V}$ (SHE) for 10 minutes in $1 \mathrm{M} \mathrm{KCl}$. Elapsed sputter time: (a) $0 \mathrm{~s}$; (b) $210 \mathrm{~s}$; (c) $330 \mathrm{~s}$; (d) $550 \mathrm{~s}$. 


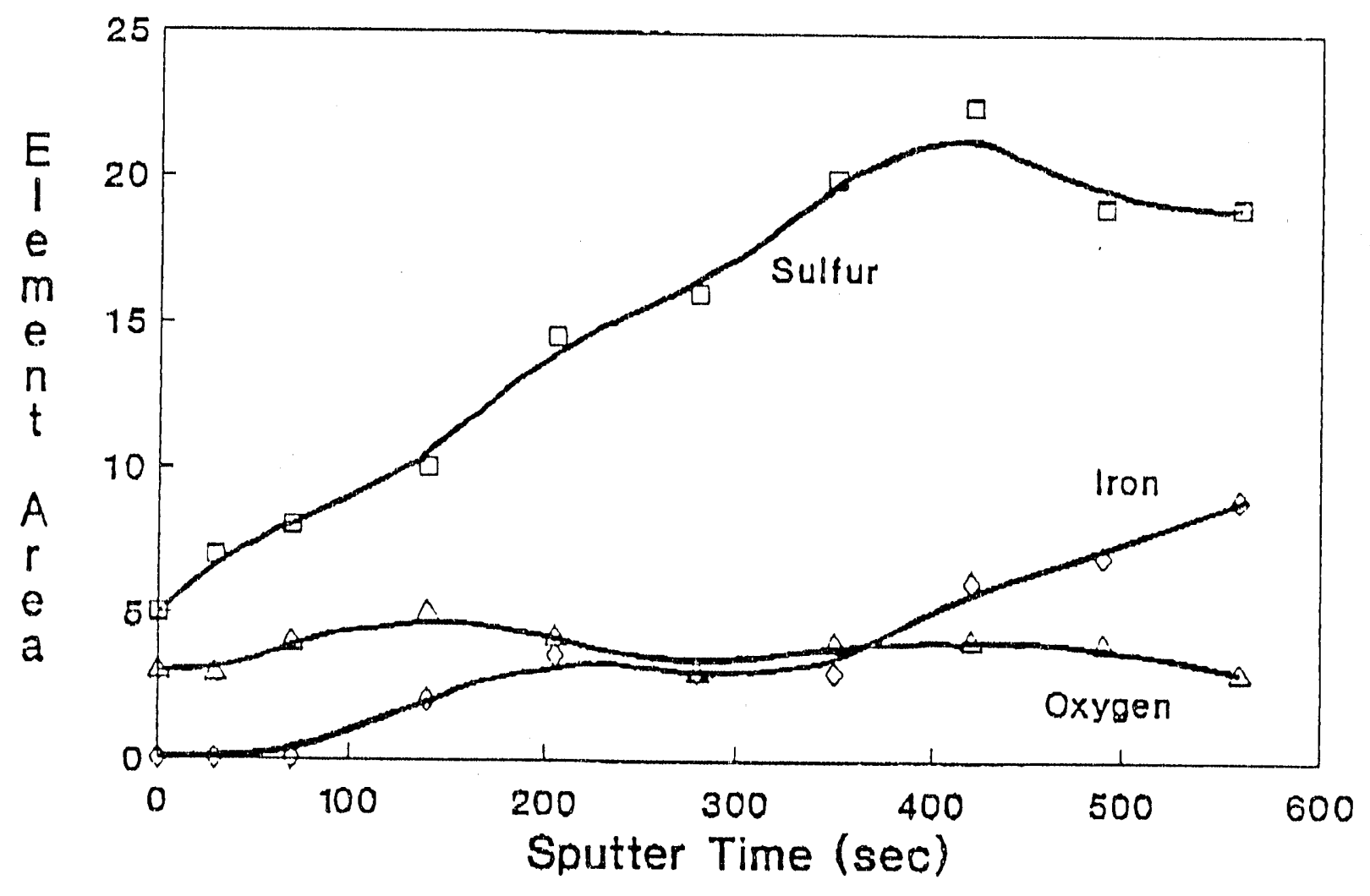

Figure 6. Low energy sputter depth profile of coal pyrite oxidized at $0.7 \mathrm{~V}$ (SHE) for 10 minutes in $1 \mathrm{M} \mathrm{KCl}$. 


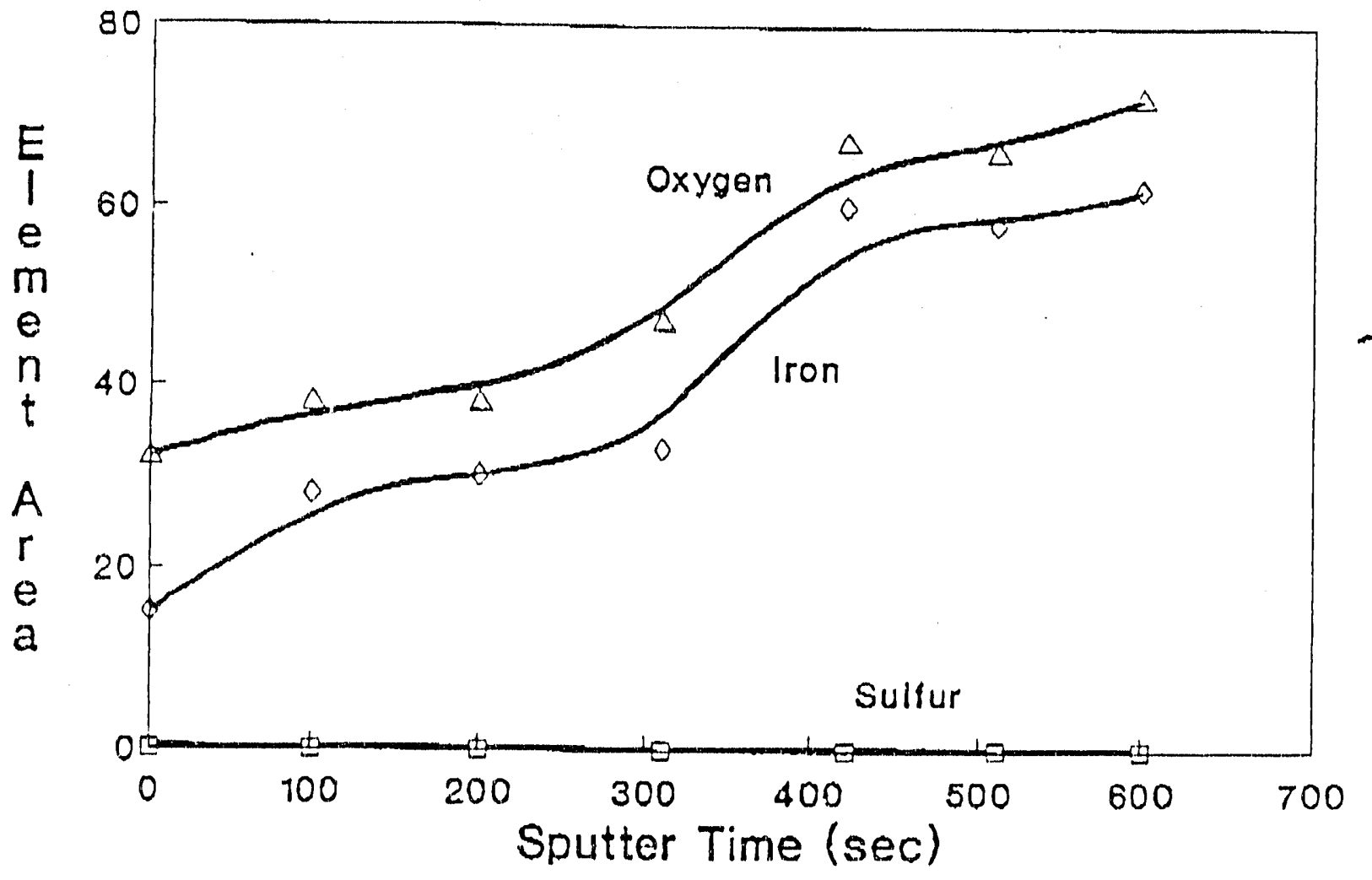

Figure 7. Low energy sputter depth profile of coal pyrite oxidized at $0.4 \mathrm{~V}$ (SHE) for 10 minutes in $1 \mathrm{M} \mathrm{KCl}$ at $\mathrm{pH} 10$. 


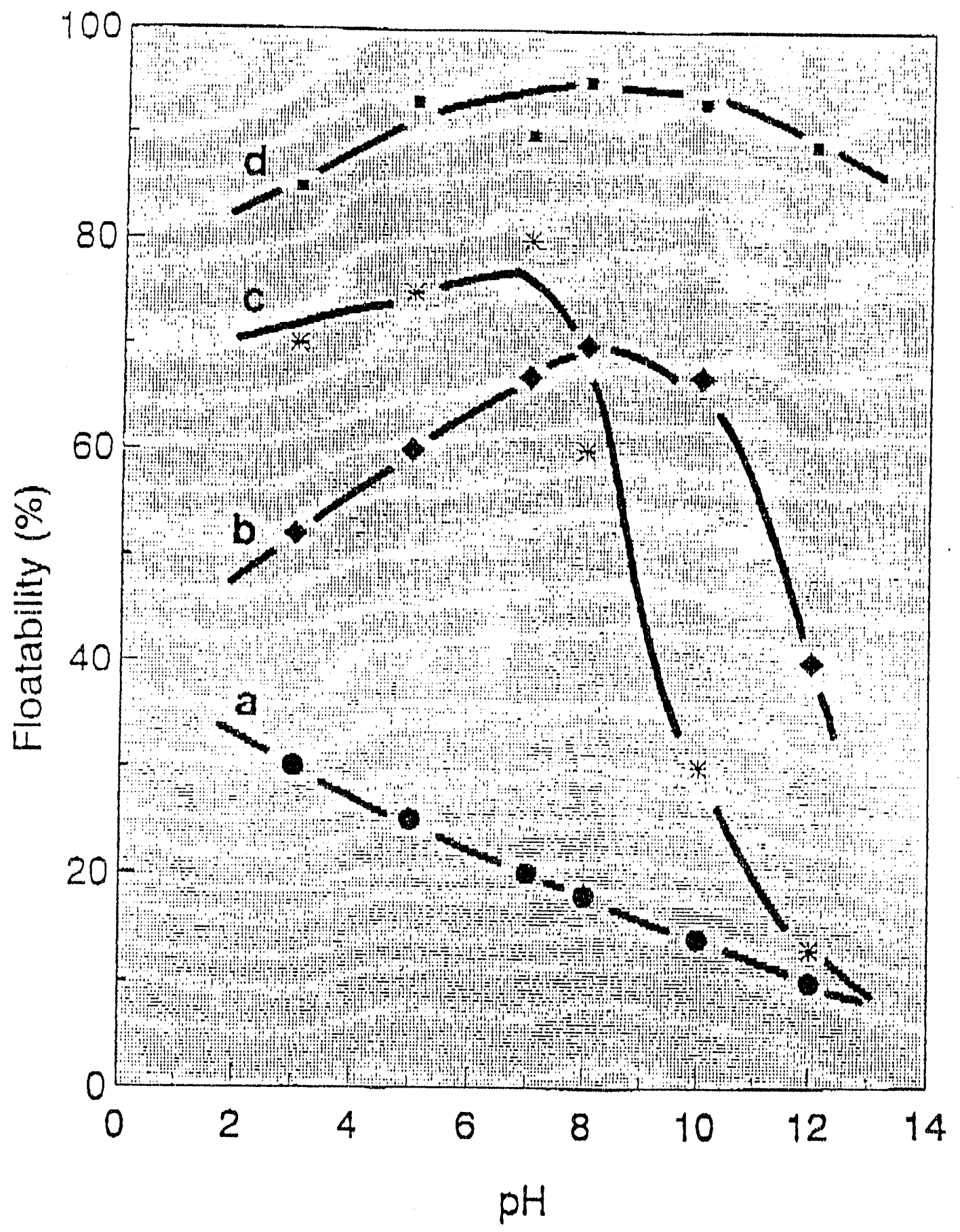

Figure 8. Floatability of Pittsburgh No. 8 seam coal pyrite as a function of pH for the following conditions: A - fresh ground, $0.25 \mathrm{lb} /$ ton Dowfroth M-150; B - fresh ground, $0.25 \mathrm{lb} /$ ton Dowfroth $\mathrm{M}-150,0.25 \mathrm{lb} /$ ton kerosene; $\mathrm{C}-30$ minutes oxidized, $0.25 \mathrm{lb} /$ ton Dowfroth $\mathrm{M}-150$; and $\mathrm{D}$ - coal contaminated pyrite particles, $0.25 \mathrm{lb} /$ ton Dowfroth $\mathrm{M}-150,0.25 \mathrm{lb} /$ ton kerosene. 

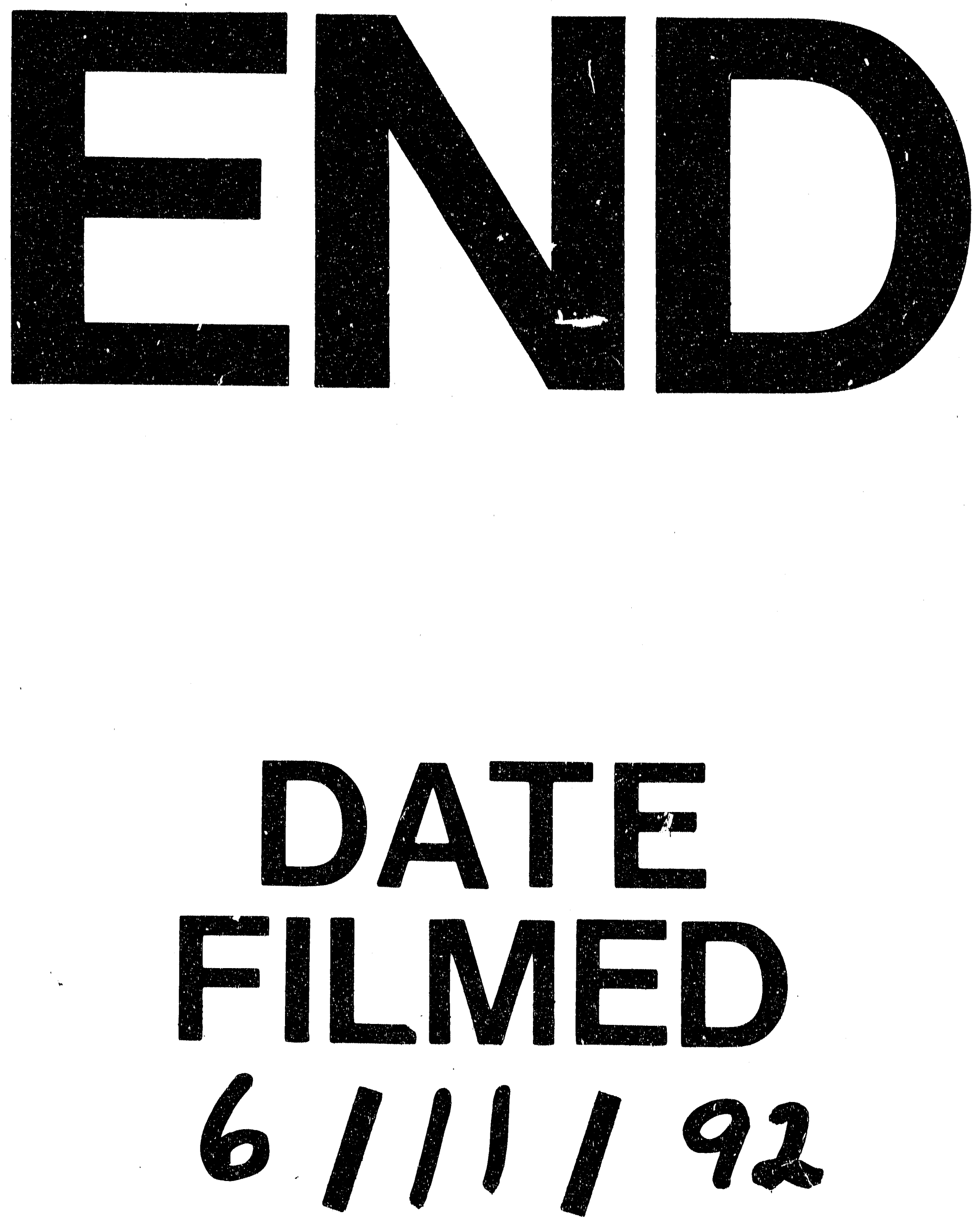

f 
